\title{
Effects of Optimized Water Management on the Uptake and Translocation of Cadmium and Arsenic in Oryza Sativa L. In Two Contaminated Soils
}

Qiongli Bao ( $\sim 15900343312 @ 163 . c o m)$

Agro-Environmental Protection Institute

Wankui Bao

Institute of Agricultural Resource and Regional Planning, China Academy of Agriculutral Science, China

Yongzhen Ding

Agro-Envrionmental Protection Institute, Ministry of Agriculture and Rural Affairs

Yizong Huang

Agro-Envrionmental Protection Institute, Ministry of Agriculture and Rural Affairs

\section{Research Article}

Keywords: Optimized water management, Cadmium, Arsenic, Rice, Amino acids.

Posted Date: June 1st, 2021

DOI: https://doi.org/10.21203/rs.3.rs-370900/v1

License: @ (i) This work is licensed under a Creative Commons Attribution 4.0 International License. Read Full License

Version of Record: A version of this preprint was published at Environmental Science and Pollution Research on August 11th, 2021. See the published version at https://doi.org/10.1007/s11356-021-15570-2. 


\section{Abstract}

Pot experiments were conducted to identify the most efficient water management strategy for reducing $\mathrm{Cd}$ and As accumulations and amino acid (AA) synthesis in rice in two soils with different $\mathrm{Cd}$ and As contents. A treatment consisting of five days of flooding followed by three days of drainage (F5D3, repeated every eight days) was identified as the most effective treatment for simultaneously decreasing $\mathrm{Cd}$ and $\mathrm{As}$ in grains, with reductions of grain $\mathrm{Cd}$ and As contents of more than $80.0 \%$ and $73.1 \%$, respectively, compared with either a drained treatment or a flooded treatment alone; this is probably related to the high efficiency of the F5D3 treatment in reducing dissolved Cd and As according to its minimum "trade-off value", due to the variations in grain $C d$ and As contents were significantly correlated with the variations in soil solution $C d\left(R^{2}=0.98\right)$ and $A s\left(R^{2}\right.$ $=0.92, p=0.0001)$ concentrations. Additionally, grain Cd content was also significantly related to the organs Cd contents (especially root $C d$ content, $R^{2}=0.99$ ) and the root-to-shoot $C d$ translocation factors $\left(R^{2}=0.99\right.$ ), whereas grain As content was significantly related to soil Eh $\left(R^{2}=-0.82, p=0.003\right)$ and $p H\left(R^{2}=0.88, p=0.0008\right)$. The AA contents in organs under the F5D3 treatment were lower than those under the Flooded and Drained treatments. These results indicated that the F5D3 treatment was the most effective water management strategy for simultaneously reducing grain $\mathrm{Cd}$ and As contents and AA synthesis in rice, which was probably due to there being no need for rice to synthesize abundant AAs to chelate metal ions.

\section{Introduction}

Cadmium (Cd) is a highly toxic heavy metal. Because its effects on animals are cumulative, it is toxic to livestock and humans at lower concentrations than to plants. The Joint Expert Committee on Food Additives (JECFA) has established a health-based guidance value for $\mathrm{Cd}$ ( $25 \mathrm{\mu g} \mathrm{kg}^{-1}$ bodyweight per month) (Joint FAO/WHO Expert Committee, 2010), and the Codex Alimentarius Commission has adopted a maximum concentration of $0.4 \mathrm{mg} \mathrm{kg}^{-1}$ for Cd in white rice grain (Codex Alimentarius, 2006).

Arsenic (As) is a carcinogen harmful to the human body. As exists in soil in many chemical forms, including inorganic As and methylated-As species like monomethylarsonic acid (MMA) and dimethylarsinic acid (DMA). As mainly exists in the form of inorganic As in soil and is easily taken up by plants (Takahashi et al., 2004). It is noteworthy that rice provides the greatest source of dietary intake of inorganic As in China (Li et al., 2011). A provisional tolerable weekly intake of $15 \mu \mathrm{g} \mathrm{kg}^{-1}$ body weight has been set by the JECFA. The national food standard limits of Cd and As are $0.2 \mathrm{mg} \mathrm{kg}^{-1}$ for rice in China (GB27622017).

Numerous studies have found that water management influences the bioavailability of Cd (Kikuchi et al., 2008; Liu et al., 2019) and As (Hua et al., 2011; Spanu et al., 2012) in soils. When the soil is flooded, the soil has a low redox potential, and any Cd and sulfur (S) in soil combine to form CdS. The solubility of CdS in water is low (Porter et al., 2004), which reduces the absorption of Cd by plants (Fulda et al., 2013). When the soil is drained (oxidative condition), CdS is converted into $\mathrm{CdSO}_{4}$ (through oxidation of $\mathrm{CdS}$ to $\mathrm{Cd}^{2+}$ and $\mathrm{SO}_{4}{ }^{2+}$ ), which enhances the availability of Cd for plant absorption (Porter et al., 2004) because $\mathrm{CdSO}_{4}$ has much higher solubility than $\mathrm{CdS}$. On the contrary, under drainage conditions, $\mathrm{As}(\mathrm{V})$ is the predominant inorganic As species and is easily combined with Fe and Al (hydr)oxides (Goldberg, 2002), thereby decreasing its mobility and its absorption by plants. When soil is flooded, As is released from the solid phase into the aqueous solution phase by the dissolution of Fe and Al(hydr)oxides and the reduction of As from As (V) to As (III), which has enhanced solubility compared with As (V) (Takahashi et al., 2004) and is easily taken up by plants.

$\mathrm{Cd}$ and As bioavailability and solubility are regulated by the alternation of high and low Eh and $\mathrm{pH}$ conditions in soil and primarily determine the $\mathrm{Cd}$ and As contents in rice grains. Accordingly, the contents of $\mathrm{Cd}$ and As in grains can be controlled through water management during the growing stage. Several studies have confirmed that under alternating wet and dry conditions, a trade-off relationship exists between $\mathrm{Cd}$ and $\mathrm{As}$ bioavailability that regulates the accumulation of $\mathrm{Cd}$ and $\mathrm{As}$ in grains (Arao et al., 2009; Hu et al., 2013; Honma et al., 2016). Until now, few comparative and simultaneous studies on the efficiency of optimized water management regimes to reduce $\mathrm{Cd}$ and As absorption and translocation in rice organs and on the synthesis of amono acids (AAs) in rice organs in both high and low compound polluted soils have been conducted. In the 
present study, a pot experiment was conducted to investigate the $\mathrm{Cd}$ and As contents and the synthesis of AAs in rice organs induced by optimized water management.

\section{Materials And Methods}

\subsection{Description of soil properties}

Two paddy soils $(0-20 \mathrm{~cm}$ ) were collected from the rice field in the Wangcheng (abbreviated as W soil) district, in Changsha city, and in Helonghu town (abbreviated as $\mathrm{H}$ soil), Xiangyin county in Hunan province, China, in February in 2018. These two soils were typical Cd-and As-polluted paddy soils with different degrees of pollution in China. The soils were air-dried and sieved to $<2 \mathrm{~mm}$ to prepare them for the pot experiments. The soil characteristics are shown in Table 1.

Table 1

The characteristics of two paddy soils. The soils were collected from rice fields in Wangcheng (abbreviated as W soil) and Helonghu town (abbreviated as $\mathrm{H}$ soil).

\begin{tabular}{|llllllll|}
\hline Soils & $\begin{array}{l}\text { TN } \\
\text { (\%) }\end{array}$ & TP & TK & TC & pH & Cd & As \\
\hline W & $0.16 \pm 0.01$ & $0.55 \pm 0.03$ & $1.47 \pm 0.12$ & $1.93 \pm 0.14$ & $6.2 \pm 0.01$ & $1.125 \pm 0.13$ & $50.32 \pm 2.54$ \\
\hline H & $0.23 \pm 0.05$ & $0.88 \pm 0.05$ & $1.46 \pm 0.10$ & $2.22 \pm 0.21$ & $6.8 \pm 0.02$ & $3.025 \pm 0.17$ & $86.56 \pm 9.83$ \\
\hline $\begin{array}{l}\text { Note: TN, TP, TK, and TC mean total nitrogen, total phosphorus, total potassium, and total carbon, respectively. Data } \\
\text { presented are the mean of 4 samples from each paddy soil. }\end{array}$
\end{tabular}

Seeds of conventional indica two-line hybrid rice (Tanliangyou 83) were chosen for the experiments. The cultivation process of rice seedlings was conducted following Feng et al. (2013). The sieved soils were transferred into $6 \mathrm{~L}$ polyvinyl chloride pots $(5$ $\mathrm{kg}$ of soil per pot). Tap water was added to pots on a daily basis to maintain a flooded condition for one month before the transplanting of rice seedlings, when six plants were transferred into each pot. The pot cultivation was conducted in a greenhouse, where five different water management methods (three experimental treatments and two controls) were practiced in the pots from the elongation stage to the flowering stage of rice. The three optimized water management methods included F5D3 ( $5 \mathrm{~d}$ flooding followed by $3 \mathrm{~d}$ drainage, and repeated every $8 \mathrm{~d}$ ), F5D5 ( $5 \mathrm{~d}$ flooding followed by $5 \mathrm{~d}$ drainage, and repeated every $10 \mathrm{~d}$ ), and F5D7 ( $5 \mathrm{~d}$ flooding followed by $7 \mathrm{~d}$ drainage, and repeated every $12 \mathrm{~d}$ ); as controls, we used continuously flooded soils, which remained anaerobic, and continuously drained soils, which remained aerobic, and we hereafter refer to these controls as the Flooded and Drained treatments, respectively. Each treatment was performed with four replicates. The basic $\mathrm{P}$ and $\mathrm{K}$ chemical fertilizers $\left(\mathrm{P}_{2} \mathrm{O}_{5} / \mathrm{K}_{2} \mathrm{O}=1: 1.5\right)$ were applied at a rate of $0.06 \mathrm{~g} \mathrm{~kg}^{-1}$ of dry weight of soil, and the urea application rate was $0.5 \mathrm{~g} \mathrm{~kg}^{-1}$ of soil dry weight. The rice seedlings were transplanted on May 10, 2018. All of the pots were rearranged randomly each week until half a month before harvest. The rice was harvested on September 5, 2018.

\subsection{Sample collection and plant and soil analysis}

The harvested rice plants were rinsed carefully and separated into roots, stems, leaves, rachises, and grains. Dried tissue samples were crushed into powder. Samples were digested according to Zhao et al. (2020). The As and Cd concentrations in the digested solution were determined using inductively coupled plasma mass spectrometry (Agilent 7500a, USA). The accuracy of the $\mathrm{Cd}$ and As analyses was confirmed using standard reference materials (Cd standard solution [GSB04-17212004] and As standard solution [GSB04-1721-2004], respectively) from the Center for Standard Reference of China.

Soil redox potential (Eh) was measured using an Eh meter (Mettler-Toledo, LED501 ORP, USA). Soil solution sampling was carried out on the last day of flooding or drainage for each cycle of the wet-dry alternation by soil solution samplers (MOM Rhizon samplers, Netherlands). The total dissolved Cd and As concentrations in the soil solution were determined as described 
for the digested solution. The $\mathrm{pH}$ of the soil solution was determined using a pH meter (Sartorius PB-10, Germany) immediately upon the arrival of the soil solution at the laboratory.

We analyzed the amino acid (AA) concentrations in the husks, stems, and roots of rice. There was not enough grain material to perform AA measurements. We selected samples for testing from the Flooded, F5D3, and Drained treatments. The quantification of AAs was performed in the manner previously described by Zhao et al. (2020).

\subsection{Statistical Analysis}

All data were reported as the mean \pm SD. Tests for Multiple comparisons were conducted among the different treatments $(a=$ 0.05). The relationships between soil indices and plant variables were investigated by Pearson correlation analysis. SAS (SAS Institute, Cary, IN) software was used.

\section{Results}

\subsection{Cd and As concentrations in rice organs}

The highest and the lowest Cd concentrations in rice organs in both soils were observed in the Drained and Flooded treatments, respectively. Among the optimized water treatments (F5D3, F5D5, F5D7), the Cd concentration increased in the shoots (including leaves, stems, rachises, and grains) and gradually increased in the roots as the number of drainage days increased. The $\mathrm{Cd}$ concentrations of rice organs from the same treatment followed the order of roots > stems $>$ rachises $>$ others in $\mathrm{H}$ soil and the order of roots > stems > other parts in $\mathrm{W}$ soil. The concentrations of $\mathrm{Cd}$ in rice organs in $\mathrm{H}$ soil were higher than those in the corresponding organs in W soil (Fig. 1a-b).

The highest and the lowest As concentrations in rice organs in both soils were observed in the Flooded and Drained treatments, respectively. With an increase in the number of drainage days, we observed a gradual decrease in the As concentrations in all organs in the optimized water treatments. Within the same treatment, the order of the As concentration in each organ was roots $>$ leaves $>$ stems $>$ rachises $>$ grains in both soils (Fig. 1c-d).

\subsection{The translocation factors (TFs) of $\mathrm{Cd}$ and As in rice plants}

The transfer potential of $\mathrm{Cd}$ or As ions from one part of rice to another is calculated from the proportion of the Cd or As concentration in different parts of rice. TFs of Cd in grains/rachises were higher than TFs of Cd in rachises/stems or stems/roots within the same treatment in both soils. TFs of $\mathrm{Cd}$ in grains/rachises in different treatments followed the order of Flooded > F5D3 > F5D5 > F5D7 > Drained treatments; however, TFs of Cd in rachises/stems and stems/roots followed the order of Flooded $<$ F5D3 $<$ F5D $5<$ F5D7 $<$ Drained treatment in both soils (Fig. 2a).

In the W soil, TFs of As in rachises/stems were greater than those in grains/rachises and stems/roots in all treatments. The Drained treatment significantly decreased the TFs of As stems/roots. In the H soil, the TFs of As in grains/rachises were greater than the other TFs from the same treatment. The TFs of As in grains/rachises among the different treatments exhibited the order of Flooded > F5D5 > F5D3 > F5D7 > Drained treatment. However, the Drained treatment significantly reduced the As TFs in rachises/stems (Fig. 2b).

\subsection{Cd and As concentrations in soil solution, soil Eh, and pH}

The lowest and the highest concentrations of $\mathrm{Cd}$ in the soil solution were detected in the Flooded and Drained treatments in both soils, respectively (Fig. 3a). In both soils, the concentration of Cd in soil solution for each of the F5D3, F5D5, and F5D7 treatments was greater on the final day of drainage than it was on the final day of flooding in the corresponding treatment. In the $\mathrm{H}$ soil, the soil solution Cd concentration followed the orders of F5D3-F5 < F5D5-F5 < F5D7-F5, and F5D3-D3 < F5D5-D5 < F5D7-D7, where -F5 indicates the fifth day of flooding and -D3, -D5, and -D7 indicate the third, fifth, and seventh days of drainage, respectively. However, there was nearly no difference among the treatments in the W soil, except the Flooded treatment showed the lowest soil solution Cd concentration (Fig. 3a). The concentrations of As in the $\mathrm{H}$ soil solution were higher than those in the W soil in all treatments. The highest and lowest As concentrations were detected in the Flooded and 
Drained treatments in both soils, respectively. In both soils, the concentration of As in soil solution for each of the F5D3, F5D5, and F5D7 treatments was lower on the final day of drainage than it was on the final day of flooding in the corresponding treatment (Fig. 3b).

Soil $\mathrm{pH}$ values in $\mathrm{H}$ soil were greater than those in $\mathrm{W}$ soil in all treatments. The highest (6.96 in soil $\mathrm{W}, 7.2$ in soil $\mathrm{H}$ ) and lowest (6.3 in soil W, 6.7 in soil H) values of soil pH were observed in the Flooded and Drained treatments in both soils, respectively. Among the optimized water management treatments, soil pH followed the order of F5D3 < F5D5 < F5D7 in both soils (Fig. 3c).

The highest and lowest values of soil Eh were detected in the Drained and Flooded treatments, respectively. The soil Eh ranged from - 200-0 mV in the F5D3-F5, F5D5-F5, F5D7-F5, and Flooded treatments, but ranged from 0-300 mV in the F5D3-D3, F5D5-D5, F5D7-D7, and Drained treatments. In F5D3-D3, F5D5-D5, and F5D7-D7, more drainage days corresponded to a higher soil Eh (Fig. 3d).

\subsection{Relationships between pairs of variables related to the absorption and translocation of $\mathrm{Cd}$ and $\mathrm{As}$ in rice}

The variation in grain $\mathrm{Cd}$ was significantly and positively correlated with the variations in rachis, leave, stem, root, soil solution $\mathrm{Cd}$, Eh, the TFs of $\mathrm{Cd}$ from stems to rachises and TFs of $\mathrm{Cd}$ from roots to stems, with the variations in variables explaining 67.6-99.3\% of the variation in rachis $\mathrm{Cd}$. The concentration of $\mathrm{Cd}$ in roots was significantly influenced by the soil solution $\mathrm{Cd}$ and Eh, with the explanation of $99 \%$ and $63.7 \%$, respectively. Negative significant correlations were noticed between soil Eh and $\mathrm{pH}$ and the TFs of $\mathrm{Cd}$ from rachises to grains, but positive significant correlation was observed between soil Eh and the TFs of Cd from roots to shoots (Table 2).

Statistically significant positive correlations were found between As in grains and that in rachises, leaves, stems, roots, soil solution $\mathrm{Cd}$, and $\mathrm{pH}$, but negative significant correlation was detected between grains As and soil Eh, the variations in variables explained more than $74.8 \%$ of the variation in grains As. Positive and significant correlations were observed between roots As and soil solution As, soil $\mathrm{pH}$, and the TFs of As from rachises to grains, with the variations in variables explaining $94.9 \%, 90.2 \%$, and $65 \%$ of the variation in grains As, respectively; but negative and significant correlation was found between roots As and soil Eh, with an explanation of $87 \%$. The soil solution As was positively and significantly affected by the soil pH and the TFs of As from rachises to grains, the variations in variables explained $84.1 \%$ and $67.6 \%$ of the variation in soil solution As, respectively; but that was negatively and significantly influenced by the soil Eh, with an explanation of $70.5 \%$. In addition, the variation in soil Eh was also negatively and significantly correlated with the variation in soil $\mathrm{pH}$, with an explanation of $74 \%$. 
Table 2

Correlation analysis between pairs of variables related to $\mathrm{Cd}$ absorption and translocation in rice

\begin{tabular}{|c|c|c|c|c|c|c|c|c|c|c|c|c|}
\hline & & $X_{1}$ & $x_{2}$ & $x_{3}$ & $X_{4}$ & $X_{5}$ & $x_{6}$ & $x_{7}$ & $x_{8}$ & $X_{9}$ & $x_{10}$ & $Y$ \\
\hline \multirow[t]{2}{*}{$\mathrm{X}_{1}$} & $R^{2}$ & & 0.999 & 0.998 & 0.977 & 0.963 & & & & 0.838 & 0.962 & 0.975 \\
\hline & $\mathrm{P}$ & & $<.0001$ & $<.0001$ & $<.0001$ & $<.0001$ & & & & 0.002 & $<.0001$ & $<.0001$ \\
\hline \multirow[t]{2}{*}{$x_{2}$} & $\mathrm{R}^{2}$ & 0.999 & & 0.997 & 0.975 & 0.961 & & & & 0.825 & 0.958 & 0.971 \\
\hline & $P$ & $<.0001$ & & $<.0001$ & $<.0001$ & $<.0001$ & & & & 0.003 & $<.0001$ & $<.0001$ \\
\hline \multirow[t]{2}{*}{$x_{3}$} & $\mathrm{R}^{2}$ & 0.998 & 0.997 & & 0.986 & 0.976 & & & & 0.838 & 0.975 & 0.984 \\
\hline & $P$ & $<.0001$ & $<.0001$ & & $<.0001$ & $<.0001$ & & & & 0.002 & $<.0001$ & $<.0001$ \\
\hline \multirow[t]{2}{*}{$x_{4}$} & $\mathrm{R}^{2}$ & 0.977 & 0.975 & 0.986 & & 0.990 & 0.637 & & & 0.847 & 0.994 & 0.991 \\
\hline & $P$ & $<.0001$ & $<.0001$ & $<.0001$ & & $<.0001$ & 0.047 & & & 0.001 & $<.0001$ & $<.0001$ \\
\hline \multirow[t]{2}{*}{$X_{5}$} & $\mathrm{R}^{2}$ & 0.963 & 0.961 & 0.976 & 0.990 & & & & & 0.820 & 0.990 & 0.987 \\
\hline & $P$ & $<.0001$ & $<.0001$ & $<.0001$ & $<.0001$ & & & & & 0.003 & $<.0001$ & $<.0001$ \\
\hline \multirow[t]{2}{*}{$x_{6}$} & $\mathrm{R}^{2}$ & & & & 0.637 & & & -0.739 & -0.742 & 0.866 & 0.676 & 0.676 \\
\hline & $P$ & & & & 0.047 & & & 0.014 & 0.014 & 0.001 & 0.031 & 0.031 \\
\hline \multirow[t]{2}{*}{$x_{7}$} & $\mathrm{R}^{2}$ & & & & & & -0.739 & & & & & \\
\hline & $P$ & & & & & & 0.014 & & & & & \\
\hline \multirow[t]{2}{*}{$x_{8}$} & $\mathrm{R}^{2}$ & & & & & & -0.742 & & & & -0.658 & \\
\hline & $P$ & & & & & & 0.014 & & & & 0.038 & \\
\hline \multirow[t]{2}{*}{$X_{9}$} & $\mathrm{R}^{2}$ & 0.838 & 0.825 & 0.838 & 0.847 & 0.820 & 0.866 & & & & 0.860 & 0.877 \\
\hline & $P$ & 0.002 & 0.003 & 0.002 & 0.001 & 0.003 & 0.001 & & & & 0.001 & 0.0008 \\
\hline \multirow[t]{2}{*}{$X_{10}$} & $\mathrm{R}^{2}$ & 0.962 & 0.958 & 0.975 & 0.994 & 0.990 & 0.676 & & -0.658 & 0.860 & & 0.993 \\
\hline & $P$ & $<.0001$ & $<.0001$ & $<.0001$ & $<.0001$ & $<.0001$ & 0.031 & & 0.038 & 0.001 & & $<.0001$ \\
\hline \multirow[t]{2}{*}{ Y } & $\mathrm{R}^{2}$ & 0.975 & 0.971 & 0.984 & 0.991 & 0.987 & 0.676 & & & 0.877 & 0.993 & \\
\hline & $P$ & $<.0001$ & $<.0001$ & $<.0001$ & $<.0001$ & $<.0001$ & 0.031 & & & 0.0008 & $<.0001$ & \\
\hline \multicolumn{13}{|c|}{$\begin{array}{l}\text { Notes: } \mathrm{X}_{1}, \mathrm{X}_{2}, \mathrm{X}_{3}, \mathrm{X}_{4}, \mathrm{X}_{5}, \mathrm{X}_{6}, \mathrm{X}_{7}, \mathrm{X}_{8}, \mathrm{X}_{9}, \mathrm{X}_{10}, \mathrm{X}_{11} \text { and } \mathrm{Y} \text { represent the } \mathrm{Cd} \text { concentration in rachises, Cd concentration in leaves, } \\
\text { Cd concentration in stems, Cd concentration in roots, Cd concentration in soil solution, soil Eh, soil } \mathrm{pH} \text {, TFs of Cd from } \\
\text { rachises to grains, TFs of Cd from stems to rachises, TFs of Cd from roots to stems, and Cd concentration in grains, } \\
\text { respectively; } \mathrm{R}^{2} \text { is the Pearson correlation coefficient. } P \text { values indicate significant correlations at the } 1 \% \text { and } 5 \% \text { levels. }\end{array}$} \\
\hline
\end{tabular}


Table 3

Correlation analysis between pairs of variables related As absorption and translocation in rice

\begin{tabular}{|c|c|c|c|c|c|c|c|c|c|c|}
\hline & & $x_{1}$ & $x_{2}$ & $x_{3}$ & $X_{4}$ & $x_{5}$ & $x_{6}$ & $x_{7}$ & $x_{8}$ & $Y$ \\
\hline \multirow{2}{*}{$x_{1}$} & $\mathrm{R}^{2}$ & & 0.877 & 0.906 & 0.790 & & -0.869 & 0.675 & & 0.748 \\
\hline & $\mathrm{P}$ & & 0.0009 & 0.0003 & 0.006 & & 0.001 & 0.032 & & 0.012 \\
\hline \multirow[t]{2}{*}{$x_{2}$} & $\mathrm{R}^{2}$ & 0.877 & & 0.941 & 0.955 & 0.858 & -0.877 & 0.816 & & 0.922 \\
\hline & $\mathrm{P}$ & 0.0009 & & $<.0001$ & $<.0001$ & 0.001 & 0.0008 & 0.003 & & 0.0001 \\
\hline \multirow[t]{2}{*}{$x_{3}$} & $\mathrm{R}^{2}$ & 0.906 & 0.941 & & 0.933 & 0.832 & -0.905 & 0.832 & & 0.925 \\
\hline & $P$ & 0.0003 & $<.0001$ & & $<.0001$ & 0.002 & 0.0003 & 0.0028 & & 0.0001 \\
\hline \multirow[t]{2}{*}{$X_{4}$} & $\mathrm{R}^{2}$ & 0.790 & 0.955 & 0.933 & & 0.949 & -0.870 & 0.902 & 0.650 & 0.965 \\
\hline & $P$ & 0.006 & $<.0001$ & $<.0001$ & & $<.0001$ & 0.001 & 0.0003 & 0.041 & $<.0001$ \\
\hline \multirow[t]{2}{*}{$X_{5}$} & $\mathrm{R}^{2}$ & & 0.858 & 0.832 & 0.949 & & -0.705 & 0.841 & 0.676 & 0.924 \\
\hline & $\mathrm{P}$ & & 0.001 & 0.002 & $<.0001$ & & 0.022 & 0.002 & 0.031 & 0.0001 \\
\hline \multirow[t]{2}{*}{$x_{6}$} & $\mathrm{R}^{2}$ & -0.869 & -0.877 & -0.905 & -0.870 & -0.705 & & -0.739 & & -0.821 \\
\hline & $\mathrm{P}$ & 0.001 & 0.0008 & 0.0003 & 0.001 & 0.022 & & 0.014 & & 0.003 \\
\hline \multirow[t]{2}{*}{$x_{7}$} & $\mathrm{R}^{2}$ & 0.675 & 0.816 & 0.832 & 0.902 & 0.841 & -0.739 & & 0.690 & 0.877 \\
\hline & $\mathrm{P}$ & 0.032 & 0.003 & 0.0028 & 0.0003 & 0.002 & 0.014 & & 0.027 & 0.0008 \\
\hline \multirow[t]{2}{*}{$x_{8}$} & $\mathrm{R}^{2}$ & & & & 0.650 & 0.676 & & 0.690 & & \\
\hline & $P$ & & & & 0.041 & 0.031 & & 0.027 & & \\
\hline \multirow[t]{2}{*}{$Y$} & $\mathrm{R}^{2}$ & 0.748 & 0.922 & 0.925 & 0.965 & 0.924 & -0.821 & 0.877 & & \\
\hline & $P$ & 0.012 & 0.0001 & 0.0001 & $<.0001$ & 0.0001 & 0.003 & 0.0008 & & \\
\hline \multicolumn{11}{|c|}{$\begin{array}{l}\text { Notes: } X_{1}, X_{2}, X_{3}, X_{4}, X_{5}, X_{6}, X_{7}, X_{8} \text {, and } Y \text { represent the As concentration in rachises, As concentration in leaves, As } \\
\text { concentration in stems, As concentration in roots, As concentration in soil solution, soil Eh, soil pH, TFs of As from rachises } \\
\text { to grains, and As concentration in grains, respectively; } R^{2} \text { is the Pearson correlation coefficient. P values indicate significan } \\
\text { correlations at the } 1 \% \text { and } 5 \% \text { levels, respectively. }\end{array}$} \\
\hline
\end{tabular}

\subsection{AA profiles in rice organs and factors influencing AAs}

The total concentrations of essential amino acids (EAAs, including Try, Met, Thr, Leu, Val, Phe, Iso, and Lys) in organs followed the order of stems $>$ husks $>$ roots within the same treatment. Thr and Val were detected as the dominant EAAs in both husks and stems, and Val and Lys were dominant in roots. Met had the lowest concentration in the plant organs, followed by Iso. The total EAA concentration decreased in husks and roots in the F5D3 treatment in W soil, mainly because of the decrease in Lys, Thr, Phe (only in roots), and Val (only in roots) concentrations. However, the total EAA concentration of stems increased gradually in the order of Flooded < F5D3 < Drained treatments in W soil, and the organs in $\mathrm{H}$ soil followed similar patterns, chiefly due to increases in the concentrations of Lys, Phe, Val, and Thr (Fig. 4a-c).

The highest total non-essential amino acid (NEAA) concentration was detected in the Drained treatment in both soils. The F5D3 treatment reduced the total NEAA concentration in both husks (mainly because of the decrease in Glu-mi and Asp concentrations) and roots (owing to the reductions in Ala, Ser, Arg, Glu, Asp, and Pro concentrations) in W soil and only in roots in $\mathrm{H}$ soil (chiefly because of the decrease in Ala, Ser, Arg, Glu-i, and Glu-a concentrations). The total NEAA concentrations in husks increased gradually in the order of Flooded < F5D3 < Drained treatment in $\mathrm{H}$ soil (reflecting an increase in the Glu-i, Asp, 
Glu-a, and Ser concentrations) and in stems in both soils (reflecting an increase in the Glu-i, Asp, Glu-a, and Ala concentrations). The total NEAA concentrations in organs exhibited the order of roots $<$ stems $<$ husks within the same treatment condition. Asp-a was the main NEAA in husks and roots, followed by Ser, Glu-a, Glu-i, and Asp-t in husks and Glu-a, Glu-i, Arg, and Cys in roots. However, the concentration of Glu-i was the highest in stems; Asp, Glu-a, Ser, and Ala were secondary NEAAs with similar concentrations among them (Fig. 4d-f).

We analyzed the correlations between the changes in amino acid concentrations in husks and the other variables (Table S2). The variations in Thr, Val, Try, Asp-a, Glu-a, and Gly concentrations positively and significantly correlated with the TFs of Cd from stems to rachises, soil solution As content, the TFs of $\mathrm{Cd}$ from stems to rachises, the TFs of Cd from rachises to grains, the TFs of $\mathrm{Cd}$ from rachises to grains, and the TFs of As from rachises to grains, respectively; the variations in those variables explained $83.1-90.4 \%$ of the variation in the concentrations of those AAs. The variations in Leu, Phe, and Cys concentrations significantly correlated with the variations in more than two other variables. The variations in both Leu and Phe concentrations significantly and positively correlated with the variations in both soil Eh and the TFs of Cd from stems to rachises, but negatively and significantly correlated with the variation in rachis As content. The variation in the Cys concentration positively and significantly correlated with grain As content and the TFs of $\mathrm{Cd}$ from rachises to grains. The variations in those variables explained $83.8-95.0 \%$ of the variation in the concentrations of those AAs. The variations in Ser and Tyr concentrations negatively and significantly correlated with soil Eh, but positively and significantly correlated with the variations in six variables, including the variations in soil $\mathrm{pH}$, the As contents of roots, leaves, stems, rachises, and grains, and the TFs of Cd from rachises to grains, with the variations in those variables explaining $81.4-95.9 \%$ of the variation in the concentrations of those AAs.

\section{Discussion}

\subsection{Effects of optimized water management treatments on Cd and As uptake and accumulation in rice}

The highest and lowest plant organ Cd concentrations were found in the Drained and Flooded treatments, respectively, but the highest and lowest plant organ As concentrations were found in the Flooded and Drained treatments, respectively. These results are similar to those reported by Arao et al. (2009), Hu et al. (2013), Wan et al. (2019), and Mlangeni et al. (2019). For both soils, the plant organ Cd concentrations were ranked in the following order: roots > other aboveground organs > grains, and this same ranking was previously reported by Xie et al. (2015). The As contents of the rice plant parts followed the pattern: roots > leaves > stems > rachises > grains in both soils, as was found by Wang et al. (2006) and Smith et al. (2008).

For reducing the $\mathrm{Cd}$ concentration of rice grains, the optimized water treatments F5D3, F5D5, and F5D7 reduced concentrations of $\mathrm{Cd}$ in grains by $80.0 \%, 64.3 \%$, and $18.5 \%$, respectively, in W soil and by $90.8 \%, 82.4 \%$, and $76.1 \%$, respectively, in $\mathrm{H}$ soil, compared with the Drained treatments, indicating that the treatment with the most days of flooding (F5D3) was more efficient than those with fewer days of flooding (both F5D5 and F5D7) at reducing grain Cd content. This result is probably attributable to the differences in soil solution Cd concentrations and soil Eh among the different treatments, which is supported by the positive and significant correlations between the $C d$ contents of grains and soil solution $\left(R^{2}=0.98, p<0.001\right)$ and between grain Cd content and soil Eh $\left(R^{2}=0.68, p=0.03\right)$, findings that are in agreement with those of Han et al. (2018). Optimized water management could lead to changes in soil Eh that influence the redox state of soil and determine the bioavailability of Cd (El-Naggar et al., 2018). After soil flooding, accompanied by a decrease in the soil Eh (Fig. 3), soil microbes respire using oxidized components, such as $\mathrm{SO}_{4}{ }^{2-}, \mathrm{NO}_{3}{ }^{-}$, and $\mathrm{Mn}(\mathrm{VI} / \mathrm{III})$ and $\mathrm{Fe}$ (III) species, and these species receive electrons and are reduced to $\mathrm{S}_{2}{ }^{-}, \mathrm{NO}_{2}{ }^{-}, \mathrm{Mn}^{2+}$, and $\mathrm{Fe}^{2+}$ (de Livera et al., 2011). CdS then forms from a combination between $\mathrm{S}^{2-}$ and Cd, which is insoluble in water (Porter et al., 2004). When soil is drained, with higher Eh, sulphate concentrations in the soil solution increased (Shaheen et al., 2016), and Cd sulphate is quite soluble (Porter et al., 2004). The concentration of dissolved Cd in the soil solution is directly correlated with the amount of absorption by plants (Lofts et al., 2004; Zhang et al., 2016). Thus, the phytoavailability of $\mathrm{Cd}$ could be manipulated using optimal water management. In addition, $\mathrm{Cd}$ accumulation in grains was 
strongly related to the $\mathrm{Cd}$ accumulations in all detected organs, (especially that in roots $\left[R^{2}=0.99, p<0.0001\right]$ ), root-to-stem Cd TFs $\left(R^{2}=0.99, p<0.0001\right)$, and stem-to-rachis Cd TFs $\left(R^{2}=0.88, p=0.0008\right)$, indicating that the accumulation of Cd in grains was closely related to that in other organs and to the translocation of $\mathrm{Cd}$ from roots to shoots. The accumulation of $\mathrm{Cd}$ in rice grains is determined by xylem-mediated Cd translocation from root to shoot and phloem-mediated Cd transport (Uraguchi et al., 2009; Kato et al., 2010). Thus, the efficient reduction of Cd content in grains could be achieved by restraining Cd accumulation in roots and inhibiting $\mathrm{Cd}$ transport from roots to shoots.

For reducing As concentrations in grains, the optimized water treatments F5D3, F5D5, and F5D7 reduced concentrations of As in grains by $77.4 \%, 77.8 \%$, and $86.7 \%$, respectively, in $\mathrm{W}$ soil and by $73.1 \%, 77.2 \%$, and $80.6 \%$, respectively, in $\mathrm{H}$ soil compared with the Flooded treatment. This indicated that the treatment with the most days of drainage (F5D7) was more efficient than those with fewer days of drainage (both F5D3 and F5D5) at reducing grain As content. These results were mainly related to the differences in soil solution As content, soil Eh, and $\mathrm{pH}$ under the different water management treatments. This is supported by the positive and significant relationships between grain As content and the soil solution As concentration $\left(R^{2}=0.92, p=\right.$ $0.0001)$ and between grain As content and soil $\mathrm{pH}\left(\mathrm{R}^{2}=0.88, \mathrm{p}=0.0008\right)$; the negative and significant relationship between grain As content and soil Eh $\left(R^{2}=-0.82, p=0.03\right)$, which was also observed in a previous study (Marin et al., 1993), also supports this. A significant negative relationship between the Eh and $p H$ in soils was also found in this study $\left(R^{2}=-0.74, p=\right.$ 0.01) (Table 2), as has previously been found by Rinklebe et al. (2016). In treatments involving more days with anaerobic conditions, the soil solution As concentration was higher than in those involving fewer days with aerobic conditions in both soils (Fig. 2b). The soil solution As concentration was positively related to soil pH but negatively related to soil Eh; these same relationships were reported in a previous study (Marin et al., 1993). When soil is drained and the accompanying increase in soil Eh and decrease in soil pH occurs (Fig. 3), As(V) becomes the predominant inorganic As species. As (V) readily combines with Fe and $\mathrm{Al}$ (hydr)oxides (Goldberg, 2002), and the resulting forms of As are less mobile and not easily absorbed by plants. When soil is flooded, soil Eh decreases and soil pH increases (Fig. 3), and As is released from those Fe and Al (hydr)oxides as As (V), which is then reduced to As (III) and readily taken up by plants. A study by Norton et al. (2012) found that the As content of rice grown in drained soil was usually 10 times lower than that of rice grown in flooded soil. Soil pH was positively and significantly correlated with the soil solution As concentration, and the variation in $\mathrm{pH}$ explained $84.1 \%$ of the variation in soil solution As concentrations (Table 2); this is consistent with the findings of Yamaguchi et al. (2011), who found that the solid/solution distribution ratio for inorganic As (III and V) decreased significantly with an increase in pH (from 5.5 to 7.0 and above). Thus, alternating between flooding and drainage in paddy fields plays an important role in the variation in soil solution As concentrations owing to its effects on soil pH and Eh, even in terms of As availability to rice plants (Takahashi et al., 2004; Arao et al., 2009; Li et al., 2009). Therefore, the most efficient means to alleviate As accumulation in rice would be to maintain aerobic conditions during the growth season (Xu et al., 2008).

Compared with the $\mathrm{W}$ soil, $\mathrm{Cd}$ and As accumulation in rice in the $\mathrm{H}$ soil was higher, which probably is related to the higher total $\mathrm{Cd}$ and As contents in $\mathrm{H}$ soil (which result mainly from industrial activities and domestic pollution), resulting in a higher soil solution Cd concentration. However, recent studies have indicated that some soils are enriched in Cd but have low Cd bioavailability. In acidic soils with relatively low total Cd contents, rice plants absorbed considerable amounts of $\mathrm{Cd}$ and accumulated higher amounts of Cd in their grains (Wen et al., 2019). Based on a GIS analysis of soil geochemical survey data, Xia et al. (2019) also noted that the spatial patterns of Cd concentrations in rice were not consistent with the soil Cd levels. These quite distinct results imply that the soil $\mathrm{Cd}$ and As pollution evaluation methods need to continue improving through best practices and take into consideration the bioavailability of $\mathrm{Cd}$ and $\mathrm{As}$.

To evaluate the degree of trade-off between soil solution As and Cd concentrations and identify the optimal water management strategy to simultaneously minimize the concentrations of both, we calculated the "trade-off value" in accordance with a report by Honma et al. (2016). The minimum "trade-off value" was observed in the F5D3 treatments in both soils, with a value of 0.86 and 0.26 in soils $W$ and $H$, respectively. Thus, the F5D3 water treatment was most effective for the simultaneous reduction of total dissolved $\mathrm{Cd}$ and $\mathrm{As}$ in both soils in this study. Among the three optimized water treatments that we tested, the F5D3 treatment also was the most efficient at concurrently reducing both the $\mathrm{Cd}$ and As contents of grains from both soils. Therefore, F5D3 makes the simultaneous reduction of $\mathrm{Cd}$ and As uptake and accumulation by rice achievable 
by keeping the soil solution Cd and As concentrations low. Honmat et al. (2016) found that a treatment with three days of flooding and five days of drainage was the most efficient for the simultaneous reduction of $\mathrm{Cd}$ and As concentrations in grains. Clearly, the optimal water management strategy identified by one or two studies is likely not applicable across all different soil types (e.g., soils with different pH values, organic matter contents, cation exchange capacities, and Cd and As contents). It is relatively difficult to reduce $\mathrm{Cd}$ and $\mathrm{As}$ simultaneously in rice grains through water regimes alone in soil polluted with both $\mathrm{Cd}$ and As.

\subsection{Effects of optimized water management treatments on the AA concentrations of organs and factors associated with the variation in individual AAs in husks}

In the F5D3 treatment, the total concentration of EAAs and NEAAs in husks and total EAAs in roots in W soil, as well as the total concentration of the NEAAs in roots in both soils, were lower compared with those of the Flooded and Drained treatments, and lower concentrations of $\mathrm{Cd}$ and As in rice organs were also detected in the F5D3 treatment compared with those detected in the Flooded or Drained treatments, which indicates that it might not be necessary for rice to synthesize abundant AAs to chelate metal ions in the F5D3 treatment. Studies in several species have indicated that many kinds of AAs (as Thr, Val, Pro, Glu, Gly, and Lys, etc.) play vital roles in plant responses to various abiotic stresses (Bowne et al., 2012; Witt et al., 2012; Obata and Fernie, 2012; Zhao et al., 2019; Yuan et al., 2020). Plant defense systems are activated under heavy metal stress, improving the synthesis of defense-related AAs. For example, His is involved in nickel chelation (Kramer et al., 1996); Pro is a radical scavenger that may participate in metal-ion chelation (Sharma and Dietz, 2006) as it is often detected in plants suffering from heavy-metal stress (Matysik et al., 2002); Glu and Gly are separately responsible for the antioxidant and heavy-metal detoxification pathways, respectively (Wu et al., 2016; Yuan et al., 2020).

The total AA concentration in husks was higher than those in the stems and roots within the same treatment (Fig. 4), but also most of the materials needed for grain filling come from the photosynthesis of the husk, and the development of the husk directly affects grain filling, and AAs in the husk certainly regulate the levels of AAs in grains. Thus, we analyzed the correlation between the changes in amino acid levels in the husks and other variables (Table S2). The results indicated that the variations in Asp-a, Glu-a, and Gly contents were closely correlated with the rachis-to-grain TFs for Cd, Cd, and As, respectively; the variation in Cys content was positively and significantly correlated with grain As content and rachis-to- grains TFs, with the variations of those variables explaining $85.5-90.4 \%$ of the variation for those AAs, as they did in Dwivedi et al. (2012). Glu and Gly are components of glutathione and phytochelatins, which are respectively responsible for the antioxidant and heavy-metal detoxification pathways (Wu et al., 2016).The improvement of Glu synthesis is a significant influencing factor for $\mathrm{Cd}$ accumulation in rice grains and may thus alleviate Cd toxicity by forming the Glu-Cd complex (Yuan et al., 2020) or synthesizing phytochelatins (PCs) and PC-Cd complexes (Pál et al., 2018). PCs have a [(Y-Glu-Cys) $]$-Gly structure and can form low molecular weight (LMW) complexes with Cd (PC-Cd) (Cobbett, 2000). The variation in Phe content displayed a close correlation with the variation in soil Eh and the variation in the TFs of Cd from stems to rachises, but it was negatively and significantly correlated with the variation in rachis As contents. The latest research shows that the change in grain Phe contents is closely related to the distribution of Cd in grains. Glu might act as the first line of defense, and Phe as the second defensive line to constrain Cd transport under Cd-stress conditions (Yuan et al., 2020). The different responses observed for AA synthesis in rice organs under optimal water management in $\mathrm{Cd}$ - and As-polluted soils may be helpful in maintaining the balance related to water resource saving and to the yield and quality of rice. Further studies should build on what we have demonstrated here and further elucidate the mechanisms underlying the interaction between water management and $\mathrm{Cd}$ and As accumulation in rice with respect to AA synthesis.

\section{Conclusions}

Optimized water management influences $\mathrm{Cd}$ and As bioavailability in paddy soils, affecting $\mathrm{Cd}$ and As absorption and translocation in rice. The F5D3 treatment was identified as the most effective treatment for simultaneously decreasing the 
accumulation of $\mathrm{Cd}$ and $\mathrm{As}$ in grains. The variation in grain $\mathrm{Cd}$ contents was significantly correlated with the variations in the soil solution Cd concentrations, plant organ Cd contents, and TFs of Cd from roots to shoots. Significant relationships were found between grain As content and soil solution As content, pH, and soil Eh. The F5D3 treatment showed high efficiency in reducing dissolved $\mathrm{Cd}$ and $\mathrm{As}$ according to the minimum "trade-off value", which is one possible reason that it simultaneously reduced grain $\mathrm{Cd}$ and As contents in both soils. The F5D3 treatment decreased the AA contents of plant organs compared with the levels observed in the Flooded and Drained treatments, and this was probably due to there being no need for rice to synthesize abundant AAs to chelate metal ions. Overall, simultaneous reductions of both $\mathrm{Cd}$ and As accumulations in grains could be realized through optimal water management in $\mathrm{Cd}$ - and As-polluted soils in an economical, efficient, and ecologically safe manner. This should be taken into consideration when carrying out current agricultural practices in contaminated soils in China.

\section{Declarations}

Authors' contributions QL B: Investigation, Methodology, Resources, Writing - Original Draft, and Funding acquisition; WK B: Conceptualization, Investigation, Methodology, Software, Writing - review, and editing; YZ D: Review; YZ H: Validation, Review, and Supervision.

Funding This work was funded by the National Key Research and Development Program of China (No. 2017YFD0801502; 2020YFC1808700), and the National Natural Science Foundation of China (No. 41807334).

Data availability All data generated or analyzed during this study were included in this published article.

\section{Compliance with ethical standards}

Conflict of interest The authors declare that they have no conflict of interest

Ethical approval All authors declared that they had no known competing financial interests or personal relationships that seemed to affect the work reported in this article. All authors followed the ethical responsibilities of this journal.

Consent to participate and publish All authors participated and approved the final manuscript to be published.

\section{Declaration of interests}

The authors declare that they have no known competing financial interests or personal relationships that could have appeared to influence the work reported in this paper.

\section{References}

1. Arao T, Kawasaki A, Baba K, Mori S, Matsumoto S (2009) Effects of water management on cadmium and arsenic accumulation and dimethylarsinic acid concentrations in Japanese rice. Environ Sci Technol 43:9361-9367.

2. Bowne JB, Erwin TA, Juttner J, Schnurbusch T, Langridge P, Bacic A (2012) Drought responses of leaf tissues from wheat cultivars of differing drought tolerance at the metabolite level. Mol Plant 5:418-429.

3. Cobbett CS (2000) Phytochelatins and their roles in heavy metal detoxification. Plant Physiol 123:825-832.

4. Codex Alimentarius (2006) Report of the 29th session of the CODEX Alimentarius Commission. CODEX Alimentarius Commission, Alinorm 06/29/41.

5. de Livera J, McLaughlin MJ, Hettiarachchi GM, Kirby JK, Beak DG (2011) Cadmium solubility in paddy soils: effects of soil oxidation, metal sulfides and competitive ions. Sci Total Environ 409:1489-1497.

6. Dwivedi S, Mishra A, Tripathi P, Dave R, Kumar A, Srivastava S, Chakrabarty D, Trivedi PK, Adhikari B, Norton GJ, Tripathi RD, Nautiyal CS (2012) Arsenic affects essential and non-essential amino acids differentially in rice grains: Inadequacy of amino acids in rice based diet. Environ Int 46:16-22. 
7. El-Naggar A, Shaheen SM, Ok YS, Rinklebe J (2018) Biochar affects the dissolved and colloidal concentrations of Cd, Cu, $\mathrm{Ni}$, and $\mathrm{Zn}$ and their phytoavailability and potential mobility in a mining soil under dynamic redox-conditions. Sci Total Environ 624:1059-1071.

8. Feng RW, Wei CY, Tu SX, Liu ZQ (2013) Interactive effects of selenium and antimony on the uptake of selenium, antimony and essential elements in paddy-rice. Plant Soil 365:375-386.

9. Fulda B, Voegelin A, Kretzschmar R (2013) Redox-controlled changes in cadmium solubility and solid-phase speciation in a paddy soil as affected by reducible sulfate and copper. Environ Sci Technol 47:12775-12783.

10. GB2762-2017. Maximum levels of contaminants in food. Chinese Food Standards Agency.

11. Goldberg S (2002) Competitive adsorption of arsenate and arsenite on oxides and clay minerals. Soil Sci Soc Am J 66:413-421.

12. Honma T, Ohba H, Kaneko-Kadokura A, Makino T, Nakamura K, Katou H (2016) Optimal soil Eh, pH, and water management for simultaneously minimizing arsenic and cadmium concentrations in rice grains. Environ Sci Technol 50:4178-4185.

13. Hu PJ, Huang JX, Ouyang YN, Wu LH, Song J, Wang SF, Li Z, Han CL, Zhou LQ, Huang YJ, Luo YM, Christie P (2013) Water management affects arsenic and cadmium accumulation in different rice cultivars. Environ Geochem Health 35:767-78.

14. Hu PJ, Li Z, Yuan C, Ouyang YN, Zhou LQ, Huang JX, Huang YJ, Luo YM, Christie P, Wu LH (2013) Effect of water management on cadmium and arsenic accumulation by rice (Oryza sativa L.) with different metal accumulation capacities. J Soil Sediment 13:916-924.

15. Hua B, Yan WG, Wang JM, Deng BL, Yang J (2011) Arsenic accumulation in rice grains: Effects of cultivars and water management practices. Environ Eng Sci 28:591-596.

16. Joint FAO/WHO Expert Committee on Food Additives (JCFA) Summary and Conclusions. Seventy-third meeting Geneva, 817 June 2010, p. 12. Available at: http://www.who.int/foodsafety/publications/chem/summary73.pdf (Accessed September, 2015).

17. Kato M, Ishikawa S, Inagaki K, Chiba K, Hayashi H, Yanagisawa S, Yoneyama T (2010) Possible chemical forms of cadmium and varietal differences in cadmium concentrations in the phloem sap of rice plants (Oryza sativa L.) Soil Sci Plant Nutr 56:839-847.

18. Okazaki M, Kimura SD, Kikuchi T, Lgura M, Hattori T, Abe T (2008) Suppressive effects of magnesium oxide materials on cadmium uptake and accumulation into rice grains-II: Suppression of cadmium uptake and accumulation into rice grains due to application of magnesium oxide materials. J Hazard Mater 154:294-299.

19. Kramer U, Cotterhowells JD, Charnock JM, Baker AJ, Smith, JA (1996) Free histidine as a metal chelator in plants that accumulate nickel. Nature 379:635-638.

20. Li G, Sun GX, Williams PN, Nunes L, Zhu YG (2011) Inorganic arsenic in Chinese food and its cancer risk. Environ Int 37:1219-1225.

21. Li RY, Stroud JL, Ma JF, McGrath SP, Zhao FJ (2009) Mitigation of arsenic accumulation in rice with water management and silicon fertilization. Envrion Sci Techno 143:3778-3783.

22. Liu YY, Xu YM, Huang QQ, Qin Xu, Zhao LJ, Liang XF, Wang L, Sun YB (2019) Effects of chicken manure application on cadmium and arsenic accumulation in rice grains under different water conditions. Environ Sci Pollut R 26:30847-30856.

23. Lofts S, Spurgeon DJ, Svendsen C, Tipping E (2004) Deriving soil critical limits for $\mathrm{Cu}, \mathrm{Zn}, \mathrm{Cd}$, and Pb: a method based on free ion concentrations. Environ Sci Technol 38:3623-3631.

24. Marin AR, Masscheleyn PH, Patrick WH (1993) Soil redox pH stability of arsenic species and its influence on arsenic uptake by rice. Plant Soil 152:245-253.

25. Matysik J, Bhalu B, Mohanty P (2002) Molecular mechanisms of quenching of reactive oxygen species by proline under stress in plants. Curr Sci 82:525-532.

26. Mlangeni AT, Perez M, Raab A, Krupp EM, Norton GJ, Feldmann J (2020) Simultaneous stimulation of arsenic methylation and inhibition of cadmium bioaccumulation in rice grain using zero valent iron and alternate wetting and drying water

Page $12 / 17$ 
management. Sci Total Enviro 711:134696.

27. Norton GJ, Pinson SRM, Alexander J, Mckay S, Hansen H, Duan GL, Islam MR, Islam S, Stroud JL, Zhao FJ, Mcgrath SP, Zhu YG, Lahner B, Yakubova E, Guerinot ML, Tarpley L, Eizenga GC, Salt DE, Meharg AA, Price AH(2012). Variation in grain arsenic assessed in a diverse panel of rice (Oryza sativa L.) grown in multiple sites. New Phytol 193:650-664.

28. Obata T, Fernie AR (2012). The use of metabolomics to dissect plant responses to abiotic stresses. Cell Mol Life Sci 69:3225-3243.

29. Pál M, Janda T, Szalai G (2018). Interactions between plant hormones and thiolrelated heavy metal chelators. Plant Growth Regul 85:173-185.

30. Porter SK, Scheckel KG, Impellitteri CA, Ryan JA (2004) Toxic metals in the environment: thermodynamic considerations for possible immobilization strategies for $\mathrm{Pb}, \mathrm{Cd}$, As, and Hg. Crit. Rev. Environ Sci Technol 34:495-604.

31. Rinklebe J, Shaheen SM, Yu K (2016) Release of As, Ba, Cd, Cu, Pb, and Sr under pre-definite redox conditions in different rice paddy soils originating from the U.S.A. and Asia. Geoderma 270:21-32.

32. Shaheen SM, Rinklebe J, Frohne T, White JR, Delaune RD (2016) Redox effects on release kinetics of arsenic, cadmium, cobalt, and vanadium in wax lake deltaic freshwater marsh soils. Chemosphere 150:740-748.

33. Sharma SS, Dietz K (2006) The significance of amino acids and amino acidderived molecules in plant responses and adaptation to heavy metal stress. J Exp Bot 57:711-726.

34. Smith E, Juhasz AL, Weber J, Naidu R (2008) Arsenic uptake and speciation in rice plants grown under greenhouse conditions with arsenic contaminated irrigation water. Sci Total Environ 392:277-283.

35. Spanu A, Daga L, Orlandoni AM, Sanna G (2012) The role of irrigation techniques in arsenic bioaccumulation in rice (Oryza sativa L.). Environ Sci Technol 46:8333-8340.

36. Takahashi Y, Minamikawa R, Hattori KH, Kurishima K, Kihou N, Yuita K (2004) Arsenic behavior in paddy fields during the cycle of flooded and non-flooded periods. Environ Sci Technol 38:1038-1044.

37. Uraguchi S, Mori S, Kuramata M, Kawasaki A, Arao T, Ishikawa S (2009) Root-to-shoot Cd translocation via the xylem is the major process determining shoot and grain cadmium accumulation in rice. J Exp Bot 60:2677-2688.

38. Wan YN, Huang QQ, Camara AY, Wang Q (2019) Water management impacts on the solubility of Cd, Pb, As, and Cr and their uptake by rice in two contaminated paddy soils. Chemosphere 228:360-369.

39. Wang FM, Chen ZL, Zhang L, Gao YL, Sun YX (2006) Arsenic uptake and accumulation in rice (Oryza sativa I.) at different growth stages following soil incorporation of roxarsone and arsanilic acid. Plant Soil 285:359-367.

40. Wen YB, Li W, Yang ZF, Zhuo XX, Guan DX, Song YX, Guo C, Ji JF (2019) Evaluation of various approaches to predict cadmium bioavailability to rice grown in soils with high geochemical background in the karst region, Southwestern China. Environ Pollut 258:113645.

41. Witt S, Galicia L, Lisec J, Cairns J, Tiessen A (2012) Metabolic and phenotypic responses of greenhouse-grown maize hybrids to experimentally controlled drought stress. Mol Plant 5:401-417.

42. Wu YJ, Zhou H, Zou ZW, Zhu W, Yang WT, Peng PQ, Zeng M, Liao BH (2016) A three year in-situ study on the persistence of a combined amendment (lime-stone+sepiolite) for remedying paddy soil polluted with heavy metals. Ecotoxicol Environ Saf 130:163-170.

43. Xia XQ, Yang ZF, Yu Tao, Zhang CS, Hou QY (2019) Predicting spatial and temporal variation of Cd concentration in rice grains in the lower Changjiang Plain during 2004-2014 based on soil geochemical survey data with GIS. J Geochem Explor 200:296-283.

44. Xie PP, Deng JW, Zhang HM, Ma YH, Cao DJ, Ma RX, Liu RJ., Liu C., Liang YG (2015) Effects of cadmium on bioaccumulation and biochemical stress response in rice (Oryza sativa L.). Ecotoxicol Environ Safe 122:393-398.

45. Xu XY, McGrath SP, Meharg AA, Zhao FJ (2008) Growing rice aerobically markedly decreases arsenic accumulation. Environ Sci Technol 42:5574-5579.

46. Yamaguchi N, Nakamura T, Dong D, Takahashi Y, Amachi S, Makino T (2011) Arsenic release from flooded paddy soils is influenced by speciation, Eh, pH, and iron dissolution. Chemosphere 83:925-932. 
47. Yuan K, Wang CR, Zhang CB, Huang YC, Wang PP, Liu ZQ (2020). Rice grains alleviate cadmium toxicity by expending glutamate and increasing manganese in the cadmium contaminated farmland. Environ Pollut 262:114236

48. Zhang S, Song J, Gao H, Zhang Q, Lv MC, Wang S, Liu G, Pan YY, Christie P, Sun WJ (2016) Improving prediction of metal uptake by Chinese cabbage (Brassica pekinensis L.) based on a soil-plant stepwise analysis. Sci Total Environ 569570:1595-1605.

49. Zhao YL, Zhang CB, Wang CR, Huang YC, Liu ZQ (2020) Increasing phosphate inhibits cadmium uptake in plants and promotes synthesis of amino acids in grains of rice. Environ Pollut 257:113496.

\section{Supplementary Information}

Supplemental Tables S1, S2 and S3 are not available with this version.

\section{Figures}
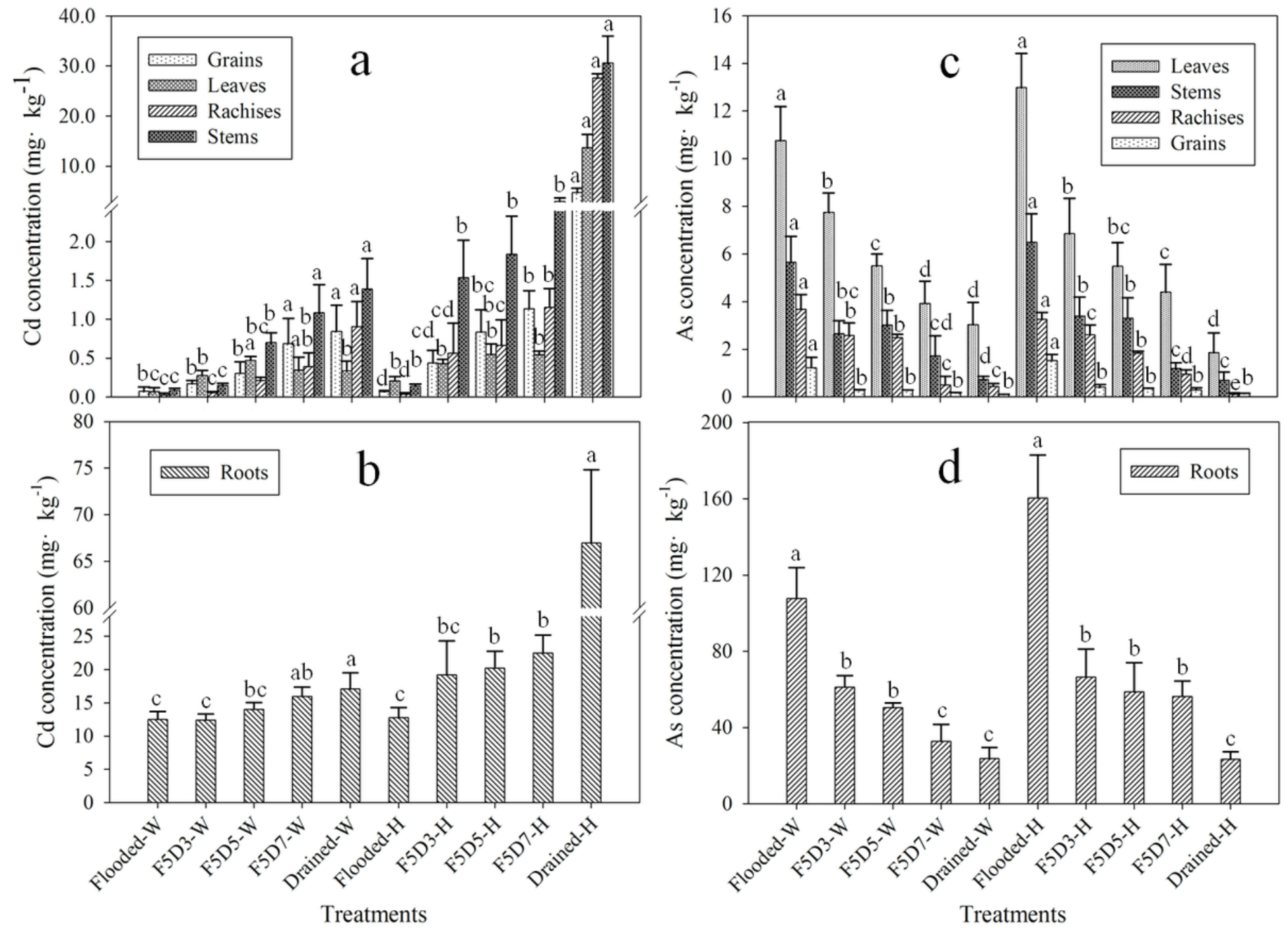

Figure 1

Effects of the optimized water management treatments on Cd concentrations in shoots (grains, rachises, leaves, and stems) (a) and roots (b), and As concentrations in shoots (grains, rachises, leaves, and stems) (c) and roots (d). A multiple comparison test was conducted among different treatments within the same organ $(a=0.05)$. The plotted columns are the mean $\pm S D(n=4)$. 

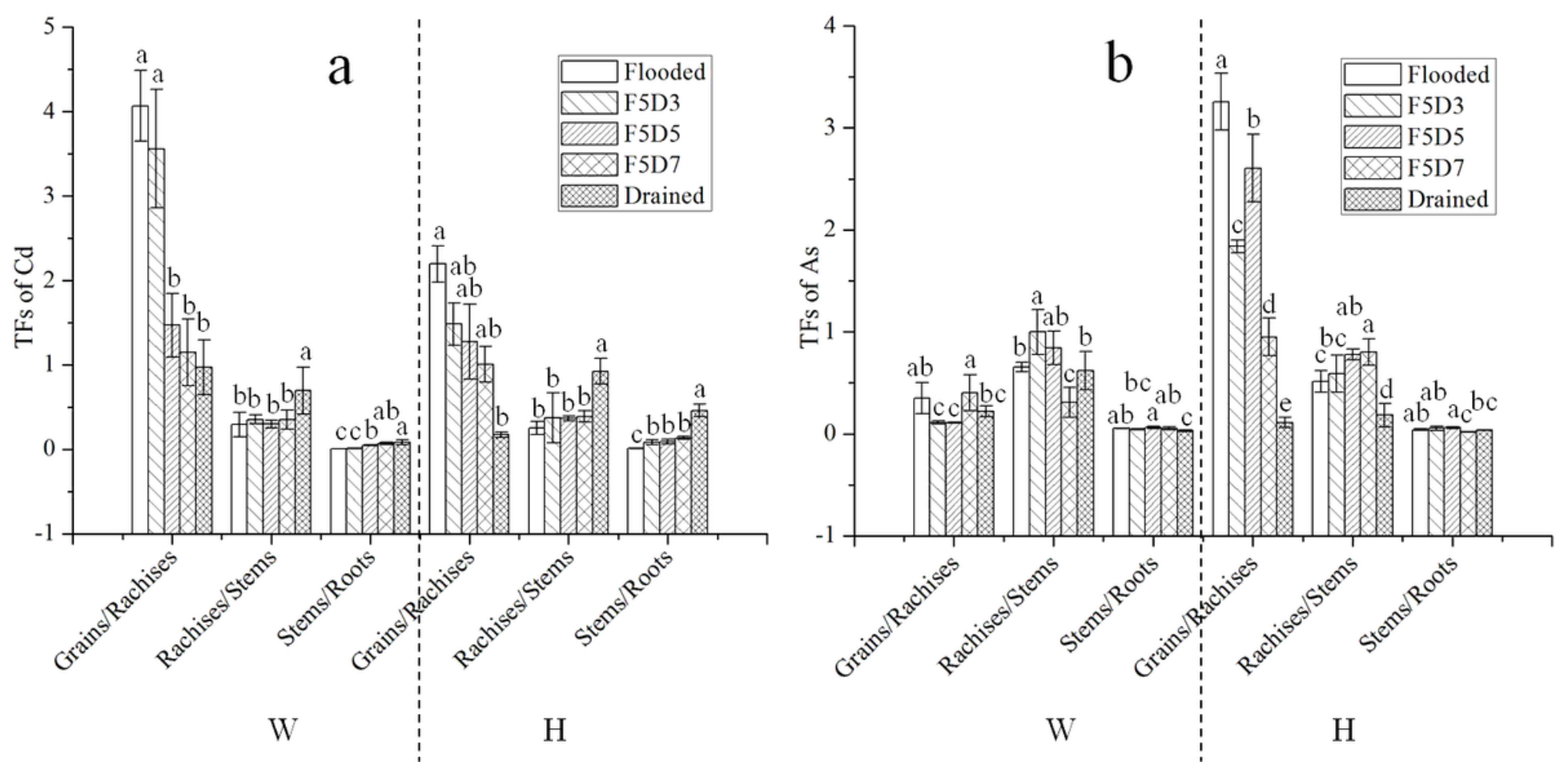

Figure 2

Effects of optimized water management treatments on the translocation factors (TFs) of Cd (a) and As (b) between the grains, rachises, stems, and roots of rice plants. A multiple comparison test was conducted among different treatments within the same TF $(a=0.05)$. The plotted columns are the mean $\pm \operatorname{SD}(n=4)$. 

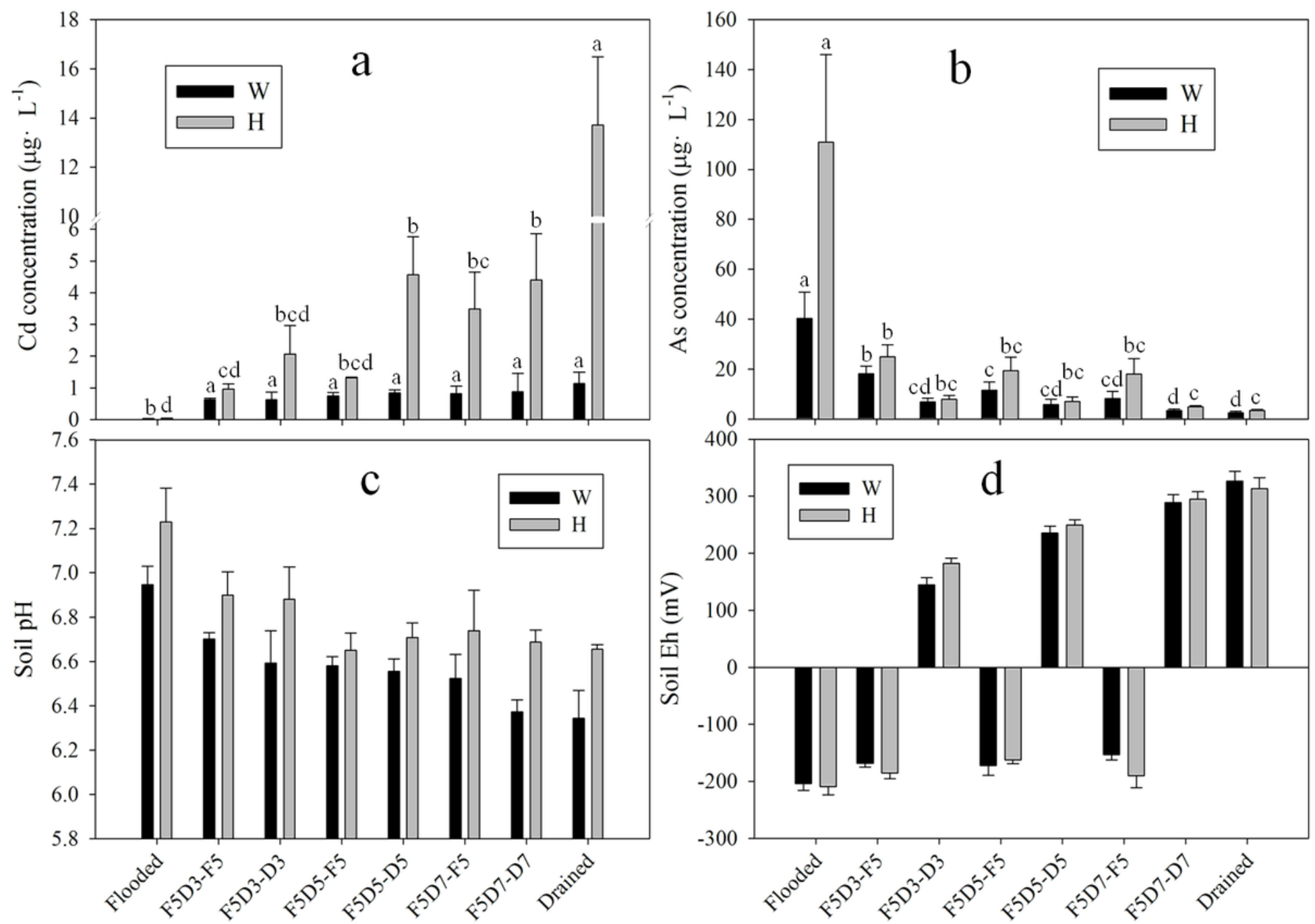

Treatments

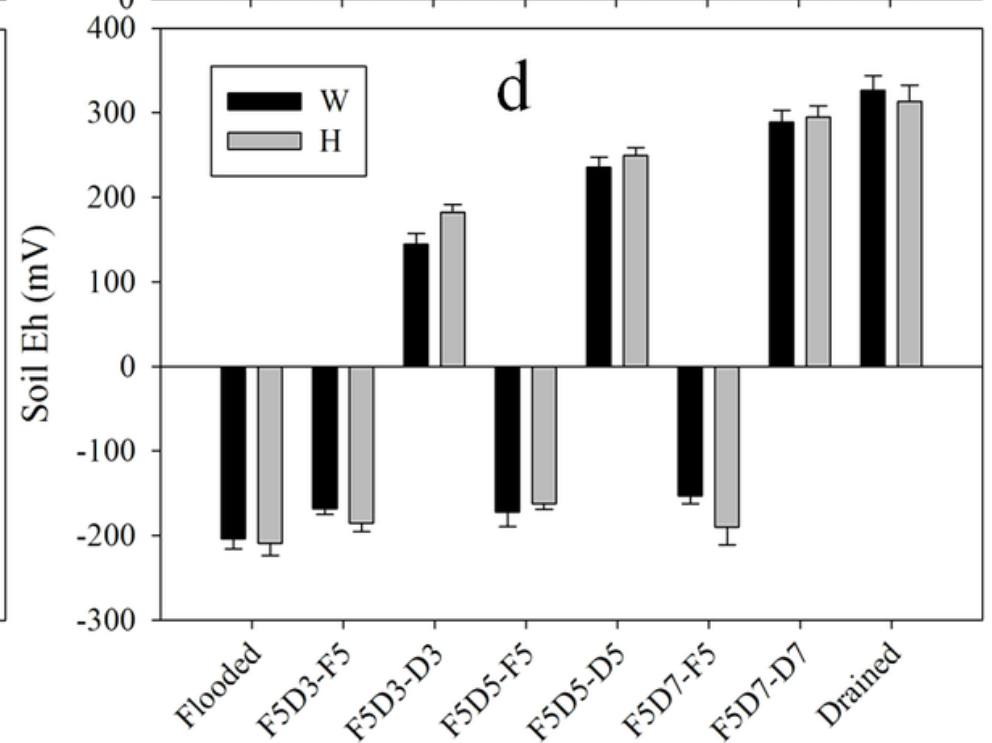

Treatments

Figure 3

Effects of optimized water management treatments on the concentrations of $\mathrm{Cd}(\mathrm{a})$ and $\mathrm{As}(\mathrm{b})$ in soil solution, soil pH (c), and Eh (d). F5D3-F5, F5D5-F5, and F5D7-F5 means the fifth day of flooding in the F5D3, F5D5, and F5D7 treatments, respectively; F5D3-D3, F5D5-D5, and F5D7-D7 means the third, fifth, and seventh days of drainage in the F5D3, F5D5, and F5D7 treatments, respectively. A multiple comparison test was conducted among different treatments within the same soil $(a=0.05)$. The plotted columns are the mean \pm SD $(n=4)$. 

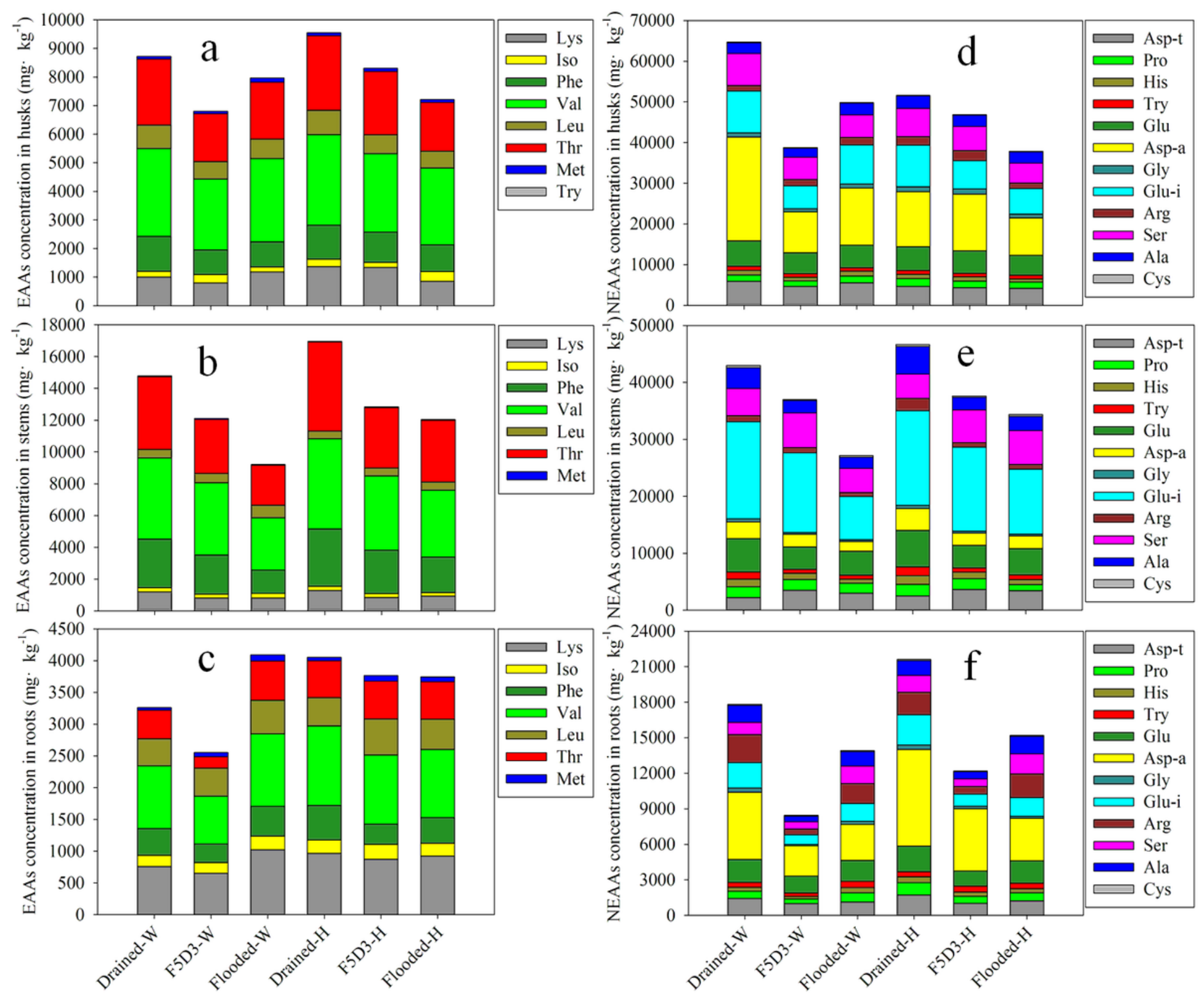

\section{Figure 4}

Effects of optimized water management treatments on the concentrations of the essential amino acids (EAAs, Tryptophan [Try], Methionine [Met], Threonine [Thr], Leucine [Leu], Valine [Val], Phenylalanine [Phe], Isoleucine [Iso], and Lysine [Lys]) and the non-essential amino acids (NEAAs, Cysteine [Cys], Alanine [Ala], Serine [Ser], Arginine [Arg], Glutamine [Glu-i], Glycine [Gly], Asparagine [Asp-a], Glutamate [Glu-a], Tyrosine [Tyr], Histidine [His], Proline [Pro], and Aspartate [Asp-t]) in the rice organs in two soils. (a), (b), and (c) represent the concentrations of EAAs in husks, stems, and roots, respectively. (d), (e), and (f) represent the concentrations of NEAAs in husks, stems, and roots, respectively.

\section{Supplementary Files}

This is a list of supplementary files associated with this preprint. Click to download.

- Graphicalabstract.tif 